\title{
Esophageal Leiomyoma with Esophagogastric Junction Outflow Obstruction at High Resolution Manometry
}

Luigi Marano*, Marianna Petrillo, Michele Grassia, Giuseppe Esposito, Angela Romano, Bartolomeo Braccio, Modestino Pezzella, Pierluigi Gallo and Natale Di Martino

$8^{\text {th }}$ General and Gastrointestinal Surgery, Department of Internal Medicine, Surgical, Neurological, Metabolic Disease and Geriatric Medicine, Second University of Naples, Naples, Italy

\begin{abstract}
Esophageal leiomyoma represents $60-80 \%$ of all benign esophageal neoplasms and rarely has been reported associated with disorder of esophageal motor activity. We discussed here a unique case of patient with leiomyoma of the middle third of the esophagus associated with esophagogastric junction outflow obstruction pattern at high resolution manometry. Thoracoscopic enucleationof a leiomyoma of the esophagus is recommended and the optimal approaches should be tailored based on the location and size of the tumor. Nevertheless the pathophysiology of manometric pattern of esophago-gastric junction outflow obstruction associated with this benign neoplasm has yet to be determined.
\end{abstract}

\author{
Publication History: \\ Received: May 23, 2014 \\ Accepted: July 17, 2014 \\ Published: July 19, 2014 \\ Keywords: \\ Esophageal leiomyoma, \\ Esophagogastric junction outflow \\ obstruction, High resolution \\ manometry
}

\section{Background}

Esophagealleiomyoma is the most common benign esophageal submucosal tumor and represents $60-80 \%$ of all benign esophageal neoplasms. This condition may be sporadic or familial, an isolated disease or associated with Alport's syndrome, and include leiomyomata within and outside of the gastro intestinal (GI) tract $[1,2]$. At least $50 \%$ of patients with esophageal leiomyoma remain asymptomatic, and these tumors are usually discovered as incidental findings during esophagography or endoscopic examination of the upper gastrointestinal tract for unrelated reasons [3]. However dysphagia is the most common symptom, followed by chest tightness and pain. Moreover esophageal leiomyomas rarely has been reported associated with disorder of esophageal motor activity $[1,4,5]$.

The conventional enucleation via thoracotomy, for patients with leiomyomas located in the upper two-thirds of thoracic esophagus, has long been the standard procedure, but the traditional open thoracotomy for enucleation of this tumor has been gradually replaced by minimally invasive thoracoscopic approaches since 1992 [6-9]. We present the first case of an esophageal leyomioma in patient with a manometric pattern of esophagogastric junction outflow obstruction on highresolution manometry who underwent surgical enucleation successfully by thoracoscopic surgery.

\section{Case Presentation}

A 47-year-old woman admitted to our hospital with dyspepsia and chest pain. There was no nausea, vomiting, or weight loss. Results of a physical examination and standard laboratory tests were normal. Barium esophagography demonstrated an image of minus in the middle third of esophagus with a little filling defect in a narrowed gastroesophageal junction. Endoscopy and endoscopic ultrasound showedthe benign esophageal neoplasm in patient with a tight gastroesophageal junction, thickened esophageal folds, and retained saliva. Computerized tomography scanning of the chest revealed a $30 \mathrm{~mm} \times 20 \mathrm{~mm}$ mass at the right medium posterior mediastinum narrowing the esophagus lumen. No evidence of infiltration in adjacent structures was detected. There were no enlarged lymph nodes, and there was no evidence for distant metastases. Esophageal high resolution manometry revealed hypertensive lower esophageal sphincter pressure with incomplete relaxation and elevated intrabolus pressure above the esophagogastric junction during preserved peristalsis (Figure 1), while multichannel intraluminal impedance and 24-hours pH-monitoringshowed normal acid reflux pattern. The minimal invasive surgical approaches for this patients included right thoracoscopic approach. The patient was intubated with a double-lumen endotracheal tube for single-lung ventilation andwere positioned in the left lateral position. Four trocars were inserted. The right lung was retracted to expose the esophagus. Intra-operative endoscopy was performed to exactly identify the tumor. During surgical exploration, a regular mass in the distal esophagus was observed and enucleated completely. The dissected area was thoroughly checked by air insufflation of the esophagus and endoluminal endoscopic inspection. Histopathologic examination revealed a tumor of $30 \mathrm{~mm} \times 20 \mathrm{~mm}$ (Figure 2) and spindle cell fascicles without mitosis or atypia was observed. Postoperative period was uneventful and the patient was discharged at $7^{\text {th }}$ postoperative day.

The patient was without dysphagia, gastro-esophageal reflux, tumor recurrence, or other related events during the three-months to oneyear of follow-up. Esophagogram, upper gastrointestinal endoscopy, and chest computerized tomography was used at 3rd month postoperatively while high resolution manometry with multichannel intraluminal impedance and 24-hours $\mathrm{pH}$ monitoring was performed at 1 year, with no pathological findings.

\section{Conclusions}

Leiomyomas are benign tumors descending from smooth muscle cells

"Corresponding Author: Marano Luigi, M.D., $8^{\text {th }}$ General and Gastrointestinal Surgery Department of Internal Medicine, Surgical, Neurological, Metabolic Disease and Geriatric Medicine, Second University of Naples, Piazza Miraglia 2, 80138 Naples, Italy, Tel: 0815665058/3341839626, Fax: 0815665055; E-mail: marano.luigi@email.it

Citation: Marano L, Petrillo M, Grassia M, Esposito G, Romano A, et al. (2014) Esophageal Leiomyoma with Esophagogastric Junction Outflow Obstruction at High Resolution Manometry. Int J Gastroenterol Disord Ther 1: 104. doi: http:// dx.doi.org/10.15344/2393-8498/2014/104

Copyright: (c) 2014 Marano L, et al. This is an open-access article distributed under the terms of the Creative Commons Attribution License, which permits unrestricted use, distribution, and reproduction in any medium, provided the original author and source are credited. 
Citation: Marano L, Petrillo M, Grassia M, Esposito G, Romano A, et al. (2014)Esophageal Leiomyoma with Esophagogastric Junction Outflow Obstruction at High Resolution Manometry. Int J Gastroenterol Disord Ther 1: 104. DOI: http://dx.doi.org/10.15344/2393-8498/2014/104

Page 2 of 2

of the esophagus; they are the most common benign tumors of the esophagus and they may occur in all parts of the esophagus, but $60 \%$ occur in the distal third, $30 \%$ in the middle, and $10 \%$ in the proximal esophagus [10].Leiomyomas grow slowly, and half of the patients are asymptomatic and the symptoms are not specific. Symptomatic patients may present with epigastric discomfort, dysphagia, weight loss, and regurgitation [11,12]. In our report, the symptoms were dyspepsia and chest pain. Esophagogastroscopy combined with endoscopic ultrasonographic evaluation of the tumor is mandatory in order to exclude cancer of esophagus from the differential diagnosis. Leiomyoma's typical appearance is of homogeneous and hypoechoic lesion with clear margin [13] which can easily be differentiated from a lipoma, cyst, or hemangiomain the esophageal wall. In our patient, highresolution manometry demonstrated an esophago-gastric junction outflow obstruction pattern according to Chicago classification and the mechanism for this pattern is unclear. This is the first case in medical literature of this association. Once the clinical diagnosis of leiomyoma is established,many factors must be considered for the optimal treatment.There is consensus in the literature that esophageal leiomyomas should be removed in symptomatic patients, they are less than $5 \mathrm{~cm}$ in size in $50 \%$ of the patients [11] and these characteristics make a minimally invasive approach appelling for the treatment of these tumors. The location of the tumor dictates the approach: a right thoracotomy or thoracoscopy is indicated when the tumor is located in the middle third in the esophagus. A left thoracotomy, thoracoscopy or a laparoscopic approach can be used for lesion in the lower third of the esophagus. An enucleation is an adequate procedure due to the benign nature of the tumor. Esophagectomy is rarely indicated, mostly in very large tumors or in the case of severe damage to the esophageal wall during the dissecation [14].In summary, this unique and undescribed case demonstrates leiomyoma of the middle third of the esophagus presenting with an esophago-gastric junction outflow obstruction pattern according to Chicago classification with the diagnosis confirmed by a combination of imaging modalities and high resolution manometry. The pathophysiology of a manometric pattern of esophago-gastric junction outflow obstruction has yet to be determined.

\section{Consent}

Written informed consent was obtained from the patient for publication of this case report and any accompanying images. A copy of the written consent is available for review by the Editor-in-Chief of this journal.

\section{Competing Interests}

Authors have no conflicts of interest or financial ties to disclose.

\section{References}

1. Gupta V, AnupamLal A, Sinha SK, Nada M, Gupta NM (2009) Leiomyomatosis of the esophagus:experience over a decade. J GastrointestSurg 13: 206-211.

2. Lee LS, Nance M, Kaiser LR, Kucharczuk JC (2005) Familial massive leiomyoma with esophageal leiomyomatosis: an unusual presentation in a father and his 2daughters. J Pediatr Surg 40: E29-E32.

3. Zaninotto G, Portale G, Costantini M, Rizzetto C, Salvador R, et al. (2006) Minimally invasive enucleation of esophageal leiomyoma. Surg Endosc 20: 19041908

4. Thomas LA, Balaratnam N, Richards DG, Duane PD (2000) Diffuse esophageal leiomyomatosis: another cause of pseudoachalasia. Dis Esophagus 13: 165-168.
5. Ray S, Saluja SS, Gupta R, Chattopadhyay TK (2008) Esophageal leiomyomatosis-an unusual cause of pseudoachalasia. Can J Gastroenterol 22 : 187-189.

6. Jiang G, Zhao H, Yang F, Li J, Li Y, et al. (2009) Thoracoscopic enucleation of esophageal leiomyoma: a retrospective study on 40 cases. Dis Esophagus 22 279-283.

7. Kent M, d'Amato T, Nordman C, Schuchert M, Landreneau R, et al. (2007) Minimally invasive resection of benign esophageal tumors. J Thorac Cardiovasc Surg 134: 176-181.

8. Everitt NJ, Glinatsis M, McMahon MJ (1992) Thoracoscopic enucleation of leiomyoma of the oesophagus. Br J Surg 79: 643.

9. Zhang W, Xue X, Zhou Q (2008) Benign esophageal schwannoma. South Med J 101: 450-451.

10. Peters JH, DeMeester TR (2005) Esophagus and diaphragmatic hernia. In: Principles of Surgery. 8th edn, Edited by Schwartz, NewYork: McGraw-Hill, p906.

11. Hatch GF 3rd, Wertheimer-Hatch L, Hatch KF, Davis GB, Blanchard DK, et al. (2000) Tumors of the esophagus. World J Surg 24: 401-411.

12. Mutrie CJ, Donahue DM, Wain JC, Wright CD, Gaissert HA, et al. (2005) Esophageal leiomyoma:a 40-year experience. Ann Thorac Surg 79: 1122-1125.

13. Asteriou C, Konstantinou D, Lalountas M, Kleontas A, Setzis K, et al. (2009) Nine years experience in surgical approach of leiomyomatosis of esophagus. World J Oncol 23: 102

14. Lee LS, Singhal S, Brinster CJ, Marshall B, Kochman ML, et al. (2004) Current management of esophageal leiomyoma. J Am Coll Surg 198: 136-146. 